\title{
Loneliness, College Belongingness, Subjective Vitality, and Psychological Adjustment during Coronavirus Pandemic: Development of the College Belongingness Questionnaire
}

\author{
Gökmen Arslan' ${ }^{10}$
}

\begin{abstract}
Loneliness is a serious risk factor for healthy development and flourishing. Although loneliness has been revealed to play an important role in psychological health and well-being, little is known about moderating and mitigating mechanisms underlying this association, especially during adverse experiences (e.g., COVID-19 pandemic). The current study purposed to explore whether subjective vitality mediated the association of loneliness with psychological adjustment and whether college belongingness moderated the mediating effect of subjective vitality on students' adjustment in the context of loneliness. The study sample comprised 333 undergraduate students (69\% female) from a public university in Turkey. They ranged in age between 19 and 41 years $(M=21.94, S D=4.15)$. Findings from mediation analysis revealed that loneliness had a significant predictive effect on subjective vitality and psychological adjustment challenges. Subjective vitality also mediated the effect of loneliness on the psychological adjustment of college students. Further, college belongingness moderated the mediating effect of subjective vitality on adjustment and had a protective effect on the association between loneliness and subjective vitality in college students. These results indicate that subjective vitality and college belongingness are important mechanisms that may help develop prevention and intervention strategies to foster students' psychological health and well-being in university settings.
\end{abstract}

Keywords: COVID-19, loneliness, subjective vitality, psychological adjustment, college belongingness, university students

Coronavirus disease (COVID-19) affects the lives of millions of people across the globe (Yıldırım \& Güler, 2020a). Recent figures showed that as of October 11, 2020, globally, there had been more than 37 million confirmed cases of COVID-19 and more than one million deaths, touching 212 countries and territories (World Health Organization, 2020). Many people infected or confirmed with COVID-19 experience a wide range of psychosocial and behavioral problems, including but not limited to depression, anxiety, social dysfunction (Yildirim \& Arslan, 2020; Tanhan, 2020), stress (Arslan et al., 2020; Tanhan, 2020), fear (Yildirim et al., 2020), higher COVID-19 related severity and preventive behaviors (Yıldırım \& Güler, 2020b), higher COVID-19 burnout (Y1ldirım \& Solmaz, 2020a), and higher loneliness and rumination (Arslan et al., 2020; Tanhan, 2020). During this public crisis, individuals with high feelings of loneliness report more maladaptive experiences (e.g., psychological adjustment challenges) and fewer

Corresponding Author: Gökmen Arslan, Department of Guidance and Psychological Counseling, Faculty of Education, Burdur Mehmet Akif Ersoy University, Burdur, Turkey.

Email: garslan@mehmetakif.edu.tr

${ }^{1}$ Department of Guidance and Psychological Counseling, Burdur Mehmet Akif Ersoy University, Burdur, Turkey 
adaptive outcomes (e.g., subjective vitality) related to the consequences of the pandemic. Such findings are alarming and needs urgent investigations focusing on individuals' mental and psychological health of during the pandemic.

Loneliness is a painful universal psychological experience that has serious consequences for college students' mental health and wellbeing (Moeller \& Seehuus, 2019; Tanhan, 2020). Loneliness is identified as people's subjective perception of deficiencies in their social connections (Russell et al., 1984) and an absence of meaningful and positive relations with other people (Weiss, 1973). This unpleasant experience occurs when a personal loss of the quantity and quality of social relationships (Arslan et al., 2020). A recent study by Peltzer and Pengpid (2017) examined the loneliness of 17,886 university students from 25 countries, indicating that $11 \%$ of students reported mostly being lonely, and $13 \%$ reported much loneliness. Similarly, Özdemir and Tuncay (2008) investigated loneliness among college students from a state university in Turkey, reporting that $60 \%$ of young adults experienced loneliness. Tanhan (2020) conducted an innovative Online Photovoice (OPV) qualitative research with 127 college students in Turkey during COVID-19, and $26 \%$ of the students reported that being alone and/or not being able to come together with other people as the most crucial issue (barrier) in their life. This finding shows how socializing is crucial because the students were not provided with any pre-items regarding loneliness and/or any other items. Therefore, loneliness is one of the significant risk factors that might contribute to psychological ill-health problems and behavioral challenges in young adulthood (Arslan, 2020; Cacioppo et al., 2006; Moeller \& Seehuus, 2019; Peltzer \& Pengpid, 2017; Tanhan, 2020).

Several studies reported that loneliness negatively impacted psychological adjustment and well-being (Arslan, 2020; Houghton et al., 2016; Mellor et al., 2008; Tanhan, 2020). Among university students, loneliness was significantly found to be associate with anxiety and depressive symptoms (Kim et al., 2017; Moeller \& Seehuus, 2019; Richardson et al., 2017; Tanhan, 2020), aggressive behaviors (Yavuzer et al., 2019), psychological well-being (Doman \& Le Roux, 2012; Satici, 2019), and addictive behaviors (Habibi et al., 2018; Skues et al., 2016). Further, some research investigated the association between loneliness and a variety of outcomes during the coronavirus pandemic. For example, Li and Wang (2020) showed that over one-third of British people reported loneliness sometimes or frequently during the pandemic and found young people at higher risk of experiencing feelings of loneliness and psychological disorders such as depression, somatic disorders. When compared to the pre-pandemic period, Killgore et al. (2020) reported increased levels of loneliness among American adults during the pandemic. They found significant positive associations between loneliness, depression, and suicidal ideation, suggesting that loneliness is a paramount health concern to cope with the pandemic effectively. College students in Turkey also reported missing their friends and social activities during the pandemic. Students reported that loneliness had adverse bio-psycho-social, spiritual, and economic impacts, in part because they used maladaptive coping strategies (Tanhan, 2020). Given the impacts of loneliness on psychological health and well-being before and during the pandemic, it is critical to understand mechanisms that may help develop prevention strategies to promote psychological adjustment and well-being in college students. The purpose of the current study is to examine whether subjective vitality mediates the association of loneliness with psychological adjustment and whether college belongingness moderates the mediating effect of subjective vitality on student adjustment in the context of loneliness.

\section{Mediating Effect of Subjective Vitality}

Subjective vitality, an increasingly prominent dynamic concept in positive psychology, refers to individuals' conscious experience of feeling alive and having energy (Ryan \& Frederick, 1997). Subjective vitality is physical and mental energy that originates from selfdirection, support, autonomy, and intrinsic motivation; this energy represents a powerful resource that helps individuals regulate for purposive actions (Ryan \& Deci, 2008; Ryan \& Frederick, 1997). People who have high subjective vitality report being more active and productive, having better coping with challenges and having more robust psychological health and wellbeing (Kawabata et al., 2017; Ryan \& Deci, 2008; Uğur et al., 2019). Within the self-determination perspective (self-determination theory; Deci \& Ryan, 2000; Ryan \& Deci, 2008), psychological energy is an essential resource for subjective vitality necessary to make activities, and a high level of vitality facilitates better psychological health and flourishing. Therefore, subjective vitality has a positive effect on the regulation of purposive behaviors and actions which enhances 
psychological health and well-being (Arslan et al., 2020). Additional research has suggested the significant and negative predictive impact of loneliness on college students' subjective vitality (Satici, 2020). Young adults with healthy social relationships reported greater subjective vitality (Akin et al., 2016; Tanhan, 2020. Vitality mediated the association between friendship quality and subjective happiness in college students (Akın \& Akın, 2015). Given the theoretical framework and empirical evidence, lonely people are more likely to report fewer aliveness and energy experiences.

Previous research also indicated that subjective vitality was associated with a variety of psychological adjustment indicators: Subjective vitality significantly correlated with subjective well-being (Jackson \& DiPlacido, 2020; Salama-Younes \& Hashim, 2018), addictive behaviors (Niemiec et al., 2010), psychological distress (Rouse et al., 2015), flourishing (Salama-Younes, 2011), school burnout (Sarıcam, 2015), and subjective happiness (Uğur et al., 2019). For Turkish college students, Arslan et al. (2020) found that subjective vitality mitigated the negative effects of coronavirus anxiety on ruminative thoughts. Similarly, internet addiction was a significant predictive of subjective happiness through subjective vitality (Akin, 2012). Another study by Uysal et al. (2013) revealed that subjective vitality, directly and indirectly, predicted subjective happiness, and Facebook addiction mediated the association between vitality and happiness in Turkish university students. Moreover, subjective vitality was positively correlated with physical function and health-related quality of life, and was negatively associated with depression, anxiety, and feelings of fatigue (Rouse et al., 2015). Although evidence is minimal, these results indicate that subjective vitality might be associated with students' psychological adjustment. Hence, we suggest that the underlying pathway from loneliness to psychological adjustment is through subjective vitality.

\section{Moderating Effect of College Belongingness}

The need for belonging is theoretically identified as a basic psychological need (Bowlby, 1969; Epstein, 1992; Glasser, 1986; Maslow, 1971) and is an essential human motivator, considering that all people are innately driven to find a sense of belongingness and sustain it (Baumeister \& Leary, 1995). School settings especially provide unique multisystemic opportunities for youths and young adults to bond (Allen et al., 2016; Arslan et al., 2020). Within the school context, the need for belonging, namely school belongingness, is a fundamental construct for the better psychological flourishing of young people (Arslan, 2020; Arslan \& Tanhan, 2019). School belonging is often defined as students' subjective feelings of being respected, accepted, included, and supported by other people in the school's social environment (Goodenow, 1993; Goodenow \& Grady, 1993). Arslan and Duru (2017) emphasize that school belonging is students' subjective perceptions of themselves as a relevant, meaningful, and valuable part of the school. Students with a high sense of school belonging exhibited fewer psychological adjustment challenges, such as depression, anxiety (Arslan, 2019; Arslan et al., 2020; Arslan \& Tanhan, 2019; Davis et al., 2019) and behavioral problems, including suicidal behaviors, conduct problems (Arslan, 2019; Arslan \& Tanhan, 2019; Olcoń et al., 2017; Rostosky et al., 2003).

Although a growing number of studies suggest the importance of school belongingness for psychological health and flourishing (see Arslan \& Duru, 2017 for a brief review), few have included college students, especially in Turkey. Researchers have often been interested in elementary and high school students. However, research focusing on a sense of belonging within the college context is crucial. Young adulthood is a time of significant career and social changes and a life stage when psychological health challenges and low flourishing can arise. For instance, Alkan (2016) investigated Psychological Sense of School Membership Scale (Goodenow, 1993) for Turkish university students and found that the scale yielded a three-factor solution (i.e., acceptance by faculty members, acceptance by students, and belonging). It also had significant correlations with loneliness, intention to dropout, satisfaction with the university, and self-report sense of belonging. College students with a high sense of belonging also reported more effective adaptive help-seeking strategies (Won et al., 2019), fewer psychological difficulties (Pittman \& Richmond, 2007; Thompson et al., 2019) and loneliness (Mounts, 2004), and higher affective well-being (Çivitci, 2014). Further, several studies showed that belongingness was an essential protective factor on students' psychological health and adjustment in the context of stressors or adversities (Backhaus et al., 2019; Civitci, 2015; Eisenberg et al., 2007; NuttmanShwartz, 2019; Zhang et al., 2020). A study by Baskin et al. (2010) reported that school belongingness had a moderating effect on the relationship between loneliness and depressive symptoms and served as a vital protective mechanism on psychological health in the context of adverse experiences (Zhang et al., 2020). 
Like the literature involving elementary and high school students, research suggests that college belongingness can be a powerful resource to foster college students' robust psychological health and wellbeing and serve as a protective mechanism in the face of loneliness experience.

\section{Purpose of This Study}

Within the empirical and theoretical evidence sketched above, the purpose of the present study is to examine the mediating effect of subjective vitality on loneliness's association with psychological adjustment. This study further examines whether college belongingness moderates the mediating effect of subjective vitality on students' adjustment in the context of loneliness, see Figure 1. Although loneliness is a serious risk factor for healthy development and flourishing, little is known about moderating and mitigating mechanisms that can help cope with the harmful effects of its psychological health and wellbeing. This relationship is particularly evident within the context of the current COVID-19 pandemic. Therefore, a critical step is understanding protective and promotive factors that may help develop prevention intervention strategies to improve college students' adjustment and well-being. In the present study, we initially investigated the College Belonging Questionnaire (CBQ) validity to measure the sense of belongingness among college students. We hypothesized that subjective vitality would mitigate the association of loneliness with psychological wellbeing, and college belongingness would moderate the mediating effect of subjective vitality in this relationship and serve as a protective factor on subjective vitality in the context of loneliness among college students.

\section{Method}

\section{Participants}

Participants comprised 333 undergraduate students (69\% female) from a state university in a Turkish urban city. Students in the study ranged between 19 and 41 years $(M=21.94, S D=4.11)$. With regards to educational level, the majority of participants were first-year students (39\%), following by second-year students (25\%), fourth-year students (19\%), and thirdyear students (17\%). Regarding the coronavirus characteristics, most participants were no infected (88\%), and approximately $60 \%$ of students reported themselves at medium-risk for COVID-19 (high-risk for COVID-19 $=8 \%$ and low-risk for COVID-19= $32 \%$ ). Moreover, approximately $41 \%$ of participants were under 20 years old and were on stay-at-home orders because of COVID-19 restrictions.

A web-based survey was employed, and participants were contacted via social media. The study announcement described it as focusing on how subjectivity vitality and college belonging are related to loneliness and psychological well-being. Participants interested in the study were directed to the survey. The survey began with informed consent and continued to the survey items. The participants completed the survey anonymously, and participation was voluntary.

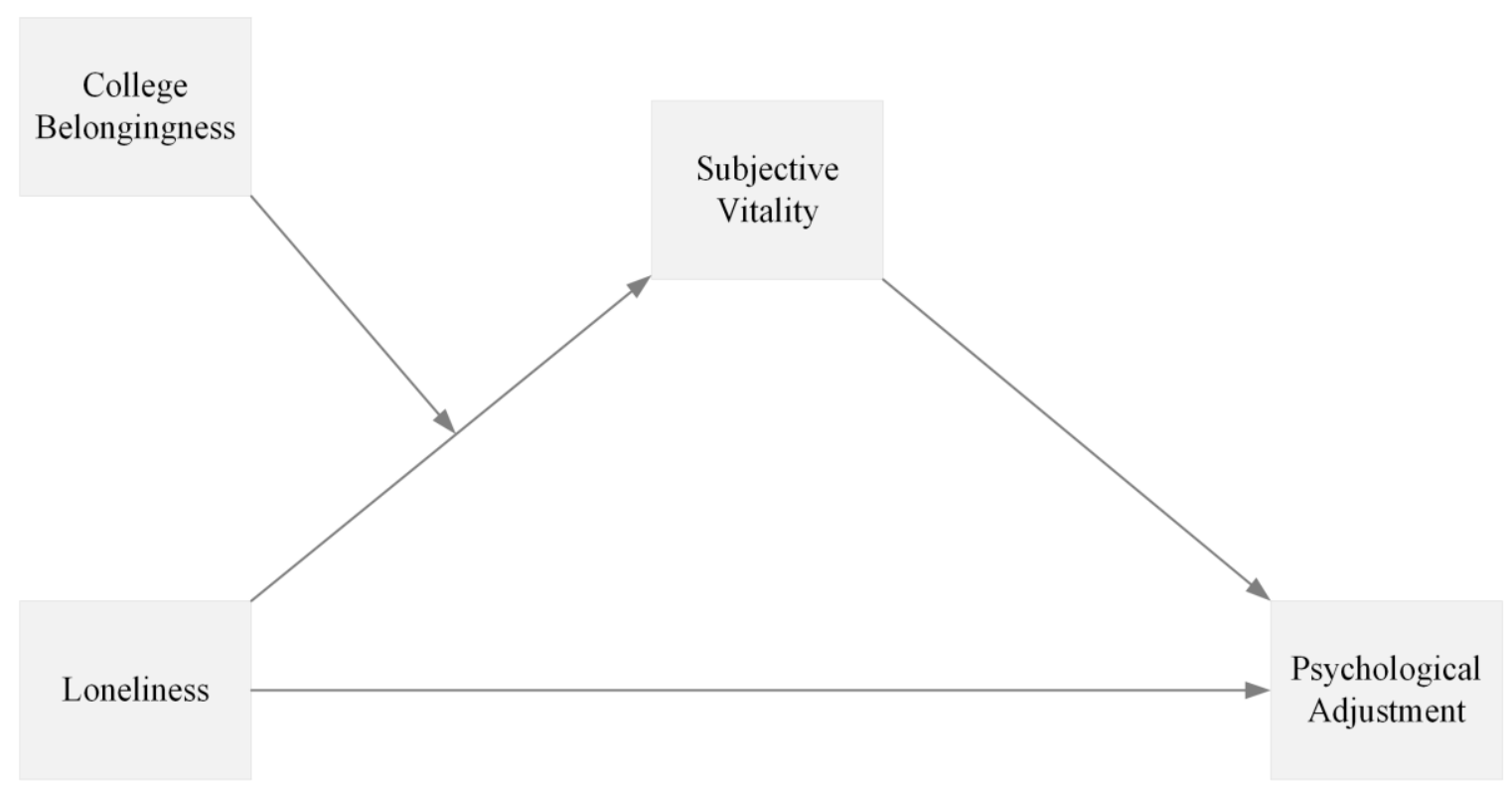

Figure I. Proposed model indicating the association between the variables of the study 


\section{Measures}

\section{College Belongingness Questionnaire (CBQ).}

The CBQ was developed for the present study. The CBQ item pool was created using a similar process to those Arslan and Duru (2017) performed in developing the School Belongingness Scale (SBS) and was reported by recommendations from research on scale development and validation (e.g., Tay \& Jebb, 2017; Worthington \& Whittaker, 2006). Items were produced to reflect the hypothesized belongingness dimensions "social acceptance or inclusion" and "social exclusion" as they are reported in the literature (e.g., Arslan \& Duru, 2017; Baumeister \& Leary, 1995; Malone et al., 2012). After reviewing the literature and theoretical framework (see Arslan \& Duru, 2017, for a brief review), six pilot items for each construct were generated to identify these themes' core characteristics. Following items drafting, a group of five experts, who were tenured associate professor and professor in the fields of counseling psychology in Turkey, independently reviewed the CBQ item pool in terms of clarity, conciseness, and developmental appropriateness. Based on their recommendations, several minor changes were provided on three items to increase clarity. The final item pool was comprised of 12 items, rating on a 7-point Likert-type scale, ranging from strongly disagree (1) to strongly agree (7). After reversing negative items of the measure (i.e., social exclusion items), overall belongingness scores are created by summing item responses. Higher scores are interpreted as a greater level of college belongingness.

UCLA Loneliness Scale (UCLA-8). The UCLA Loneliness Scale (Russell et al., 1980) was used to assess participants' loneliness feelings. The scale is an 8-item self-report measure (e.g., "I am unhappy doing so many things alone"). All items use a 4-point response scale (from $1=$ never to $4=$ often). Doğan et al. (2011) examined the scale's psychometric properties with the Turkish college sample, indicating that the measure had an adequate internal reliability coefficient $(\alpha=.72)$. The internal reliability estimate with the present sample was strong (see Table 2).

Subjective Vitality Scale (SVS). The SVS is a 7item self-report scale (e.g., "I nearly always feel awake and alert.") used to measure college students' subjective vitality of (Ryan \& Frederick, 1997). All items are scored using a 7-point Likert-type scale ranging from $1=$ not at all true to $7=$ very true. Uysal et al. (2014) investigated the Turkish version of the scale with college students, demonstrating that the scale had adequate-strong internal and test-retest reliability estimates $(\alpha=.84$, test-retest $=.74)$. The scale had a strong internal reliability estimate with the sample of the study (see Table 2).

Brief Adjustment Scale-6 (BASE). Students' psychological well-being was assessed using the BASE, a 6-item self-report instrument (e.g., "To what extent have you felt tense, anxious, and/or afraid this week?"), scored using a 7-point scale ranging from $1=$ not at all to $5=$ extremely (Cruz et al., 2020). Yildırım \& Solmaz (2020b) examined the psychometric properties of the Turkish version of the scale, showing that the measure had strong internal reliability estimate $(\alpha=.88)$. Internal reliability estimate with the present sample was strong (see Table 2).

\section{Statistical Analysis}

We first the College Belongingness Questionnaire (CBQ) using exploratory and confirmatory factor analysis. The sample of the study was randomly divided into two subsamples (about 50\%). Exploratory factor analysis was carried out to identify the factor structure of the measure using the first sample. Results from the factor analysis were interpreted using cross-loading ( $\geq$ .30), factor loading $(\geq .32)$, and theoretical interpretability (Field, 2009; Stevens, 2009). Next, confirmatory factor analysis was conducted to test the second-order measurement model with the second sample. Model fit statistics and their cut points were also used to evaluate the measurement model: CFI and TLI scores $.90 \leq=$ adequate fit; RMSEA and SRMR values $\leq .10=$ adequate fit (Hooper et al., 2008; Hu \& Bentler, 1999). We performed descriptive statistics. Analysis assumptions were examined and score skewness and kurtosis were interpreted for normality assumption (D'Agostino et al., 1990; Field, 2009). Moreover, the internal reliability estimates of the measure were examined with the sample of the present study. After reviewing these preliminary analyses, we employed a moderated mediation model using the PROCESS macro (Model 7) for SPSS version 3.5 (Hayes, 2018). Moderated mediation is a statistical approach performed to examine conditional indirect effects, and the moderation and mediation analysis is used together in the same model (Preacher et al., 2007). Given the bootstrap approach's advantageous, the bootstrap approach with 10,000 resamples to estimate the $95 \%$ confidence intervals was performed to evaluate 
Table I. Scale Items, belonging domains, and factor loadings

\begin{tabular}{|c|c|c|c|c|c|c|}
\hline \multirow[b]{2}{*}{ Items } & \multicolumn{2}{|c|}{ EFA } & \multicolumn{4}{|c|}{ CFA } \\
\hline & $\begin{array}{c}\text { SA } \\
\text { S }\end{array}$ & SES & $\lambda_{1}$ & $\ell^{2}{ }_{1}$ & $\lambda_{2}$ & $\ell_{2}^{2}$ \\
\hline Social Acceptance Scale & - & - & - & - & .49 & .24 \\
\hline I feel like I belong to this university. & .88 & .04 & .92 & .84 & - & - \\
\hline I feel like myself as a real part of this university. & .85 & -.05 & .94 & .88 & - & - \\
\hline I can really be myself at this university. & .84 & .01 & .62 & .39 & - & - \\
\hline Overall, I feel happy to be at this university. & .73 & .20 & .70 & .48 & - & - \\
\hline I think that people at this university care about me. & .70 & -.16 & .69 & .48 & - & - \\
\hline Social Exclusion Scale & - & - & - & - & .73 & .54 \\
\hline My friends generally ignore me at this university. & -.07 & .78 & .76 & .58 & - & - \\
\hline My friends do not involve me in their plans. & .04 & .62 & .67 & .45 & - & - \\
\hline I don't have close bonds with members of this university. & .03 & .50 & .56 & .31 & - & - \\
\hline I feel isolated from the rest of the world at this university. & .16 & .45 & .46 & .21 & - & 一 \\
\hline I feel myself excluded at this university. & -.09 & .39 & .64 & .41 & - & - \\
\hline Overall College Belongingness Scale & - & - & - & - & - & - \\
\hline
\end{tabular}

Note. EFA $=$ exploratory factor analyses; $\mathrm{CFA}=$ confirmatory factor analysis. $\lambda_{1}=$ item loadings for first-order factors; $\ell^{2}{ }_{1}=$ indicator reliability for first-order factor items; $\lambda_{2}=$ first-order factor loading for second-order factor; $\ell^{2}{ }_{2}=$ indicator reliability for second-order factor indicators

the significance of indirect effects (Hayes, 2018; Preacher \& Hayes, 2008). All analyses were employed using AMOS version 24 and SPSS version 25.

\section{Results}

\section{CBQ Latent Structure}

Findings from descriptive statistics indicated that several pilot items of the CBQ had relatively nonnormal distribution (skewness and kurtosis values > $|3|$ ), and exploratory factor analysis was performed using the principal axis factoring method with a Promax rotation. The first analysis indicated a two-factor solution with eigenvalues $>1.0$. It accounted for $46 \%$ of the variance, characterized by an adequate sample size (Kaiser-Meyer-Olkin test of sampling adequacy = .82 ) and a lack of singularity (Bartlett's $\chi^{2}=990.27, d f$ $=66, p<.001)$. Visual inspection of the scree plot, eigenvalues (scores >1.0), and parallel analysis suggested a two-factor solution yielded a better fit to the data; therefore, no other solutions were examined. After excluding non-loading and cross-loading items, the factor analysis was rerun. Findings from this analysis revealed the two-factor solution, which comprised of 10 items explained $49 \%$ of the variance, with eigenvalues of 4.01 and 1.82. All factor loadings on two factors had scores exceeding .32 and ranged from adequate to strong, with no cross-loadings, as shown in Table 1.

After exploring the measure's factor structure, confirmatory factor analysis was carried out to affirm the measurement model. Findings from the factor analysis provided adequate data-model fit statistics to the two-factor measurement model with 10 items that were indicators of two first-order structures (i.e., social exclusion and social acceptance), $\chi^{2}=81.59, d f=34, p$ $<.001, \mathrm{CFI}=.94, \mathrm{TLI}=.92, \operatorname{RMSEA}(95 \% \mathrm{CI})=.088$ $(.063, .11)$.

Table 2. Descriptive statistics and correlation results

\begin{tabular}{|c|c|c|c|c|c|c|c|c|c|}
\hline Variables & Mean & $S D$ & Skewness & Kurtosis & $\alpha$ & 1. & 2. & 3. & 4. \\
\hline 1. Loneliness & 14.51 & 4.68 & .79 & .17 & .79 & - & -.40 & -.54 & .34 \\
\hline 2. Subjective vitality & 27.27 & 9.93 & .27 & -.82 & .89 & & - & .43 & -.35 \\
\hline 3. College belongingness & 46.64 & 9.09 & -.66 & .45 & .81 & & & - & -.29 \\
\hline 4. Psychological adjustment & 21.45 & 10.27 & .32 & -.94 & .93 & & & & - \\
\hline
\end{tabular}

Note. All correlations were significant $(p<.001)$ 
The scales had adequate-to-strong factor loadings, ranging from .46 to .94 , as shown in Table 1 . Reliability analysis also showed that the CBQ had adequate-strong internal reliability estimates with total sample (CBQ $\alpha$ $=.81, \mathrm{SES} \alpha=.71, \mathrm{SAS} \alpha=.89$ ). These results provide initial evidence suggesting that the CBQ is psychometrically reliable and valid for assessing Turkish students' college belongingness.

\section{Descriptive Statistics}

Findings from descriptive statistics revealed that skewness scores were between -0.66 and 0.79 , and kurtosis values ranged from -0.94 to 0.45 , suggesting that all variables in the study were relatively normally distributed (D'Agostino et al., 1990; Field, 2009). Correlation results also showed that loneliness had significant and negative correlations with subjective vitality and college belonging. There are a significant and positive correlation between subjective vitality and college belonging. Psychological adjustment was significantly and negatively associated with subjective vitality and college belonging, as shown in Table 2 . Lastly, we examined the study variables' internal reliability estimates, indicating that all measures had strong internal reliability estimates, ranging from .79 to .93 , respectively.

\section{Conditional Process Analysis}

We aimed to examine whether subjective vitality mitigated the association between loneliness and psychological adjustment and whether college belongingness moderated the mediating effect of subjective vitality on this relationship. Findings from conditional process analysis revealed that loneliness significantly and negatively predicted subjective vitality $(b=-.61, t=-4.84, p<.001)$, whereas college belongingness was a significant and positive predictor of subjective vitality $(b=.36, t=5.59, p<.001)$. The interaction effect between loneliness and college belonging on subjective vitality was significant $(b=-$ $.03, t=-3.23, p=.001 ; R^{2}$ change $\left.=.03\right)$. The model accounted for $25 \%$ of the variance in subjective vitality significantly, as seen in Table 3. The simple slope effect, moreover, showed that the indirect effect of loneliness on psychological adjustment through subjective vitality was observed when college belongingness was high $(+1 S D)$, moderate, and low $(-1 S D)$, as shown in Figure 2.

We further tested the mediating effect of subjective vitality on the association between college students' loneliness and psychological adjustment. Results from mediation analysis showed that psychological adjustment was significantly and negatively predicted by subjective vitality ( $b=-.24, t=-4.19, p<.001)$, and loneliness also had a significant predictive effect on psychological adjustment ( $b=.54, t=4.43, p<.001)$. Loneliness and subjective vitality together explained $17 \%$ of the variance in psychological adjustment. These results suggest that loneliness significantly predicted psychological adjustment through subjective vitality, and subjective vitality mitigates the negative effect of loneliness on adjustment of college students, as seen in Table 3 .

\section{Discussion}

Coronavirus disease is a global health crisis impacting people's daily lives and health all over the world. The pandemic is related to a wide range of psychological, social and behavioral consequences such as feelings of loneliness (Killgore et al., 2020; Li \& Wang, 2020; Tanhan, 2020). Hence, there is a crucial need to understand the protective and mitigating factors to develop effective prevention and intervention strategies for promoting people's mental health and well-being in the context of the coronavirus pandemic's experiences. The present study examined whether subjective vitality mediated the association of loneliness with psychological well-being and whether college belongingness moderated the mediating effect of subjective vitality on students' well-being in the context of loneliness. Before testing the moderated mediation model, we explored the initial development and validation of a self-report measure, the College Belongingness Questionnaire (CBQ), for college students in Turkey, which may help assess the sense of belonging of students in university settings. Findings from factor analysis revealed a two-factor solution, which included 10 items explained $49 \%$ of the variance. The item loadings on two factors exceeding .32 and ranged from adequate to strong. After exploring the factor structure of the measure, confirmatory factor analysis provided adequate data-model fit statistics to the two-factor measurement model with 10 items that were indicators of two latent constructs (i.e., social exclusion and social acceptance). All items of the scale had adequate-to-strong factor loadings, ranging from .46 to .94 , and the CBQ had adequate-strong internal reliability estimates. These results provide initial evidence supporting the CBQ's reliability and validity for assessing Turkish students' sense of college belongingness in university settings.

Findings from the study next indicated that loneliness significantly predicted subjective vitality and psychological well-being of college students. Higher feelings of loneliness were associated with less subjective 
Table 3. Unstandardized coefficients for the conditional process model

\begin{tabular}{|c|c|c|c|c|}
\hline \multirow[b]{3}{*}{ Antecedent } & \multicolumn{4}{|c|}{ Consequent } \\
\hline & \multicolumn{4}{|c|}{$M$ (Subjective vitality) } \\
\hline & Coeff. & $S E$ & $t$ & $p$ \\
\hline$X$ (Loneliness) & -.61 & .12 & -4.84 & $<.001$ \\
\hline$W($ College belongingness $)$ & .36 & .06 & 5.59 & $<.001$ \\
\hline$X \times W$ & -.03 & .01 & -3.23 & .001 \\
\hline Constant & 26.40 & .54 & 48.63 & $<.001$ \\
\hline & \multicolumn{4}{|c|}{$\begin{array}{c}R^{2}=.25 ; R^{2} \text { change }=.03 \\
F=35.37 ; p<.001\end{array}$} \\
\hline & \multicolumn{4}{|c|}{$Y$ (Psychological adjustment) } \\
\hline$X$ (Loneliness) & .54 & .12 & 4.43 & $<.001$ \\
\hline$M$ (Subjective vitality) & -.24 & .06 & -4.19 & $<.001$ \\
\hline Constant & 28.31 & 1.68 & 16.86 & $<.001$ \\
\hline & \multicolumn{4}{|c|}{$\begin{array}{l}R^{2}=.17 \\
1.44 ; p<\end{array}$} \\
\hline
\end{tabular}

\begin{tabular}{rcccc} 
& \multicolumn{5}{c}{ Conditional indirect effects of loneliness on psychological adjustment } \\
\hline College belongingness & Coeff. & BootSE & BootLLCI & BootULCI \\
\hline$M-1 S D(-.9 .10)$ & .07 & .04 & .01 & .16 \\
$M(.00)$ & .15 & .05 & .07 & .26 \\
$M+1 S D(9.10)$ & .22 & .07 & .010 & .38 \\
\hline \multicolumn{7}{c}{ Index of moderated mediation } \\
\hline College belongingness & .01 & .01 & .01 & .02 \\
\hline
\end{tabular}

Note. $S E=$ standard error. Coeff = unstandardized coefficient. $X=$ independent variable; $M=$ mediator variable; $W=$ moderator variable; $Y=$ outcomes or dependent variable

vitality and more psychological adjustment challenges. These results suggest that lonely young adults are more likely to have lower subjective vitality and psychological well-being than nonlonely young adults. With the spread of coronavirus, most countries issued varying stay-at-home orders mandating that nonessential businesses and schools close. Although these measures are critical to decreasing the infection rate, people are more likely to experience feelings of loneliness because of limiting social interactions, contacts, or activities (Luchetti et al., 2020). For example, at the beginning of the pandemic, young people under 20 years had mandated stay-at-home orders because of Turkey's COVID-19 restrictions, which may have limited social activities and interactions. Thus, young people may thus be at higher risk for increases in feelings of loneliness due to the restriction measures. Results from this study are consistent with these findings provided from the context of the COVID-19 pandemic. Arslan and Yildırım (2020) demonstrated that subjective vitality and loneliness could be important mediators between coronavirus anxiety and loneliness among college students. Tanhan (2020), in an online photovoice
(OPV) study, found that $18 \%$ of the Turkish college students reported having social connections with other people and especially family, friends, and peers as the most important facilitator for themselves during the pandemic. In the same study, $26 \%$ of the participants reported having no social connections and support as the most important barrier (issue, problem) during the pandemic.

Social interactions with others influence one's thoughts, behaviors, and feelings which enhance positive experiences (e.g., subjective vitality) and psychological well-being. However, feelings of loneliness result from both a lack of intimate, meaningful relatedness to another individual (emotional loneliness) and insufficient social relationships. The person is part of a group of individuals who share similar interests and activities (Russell et al., 1984). Given the COVID-19 restrictions in Turkey, college students are more likely to experience greater loneliness because of insufficient social interactions with others. Lonely young adults may thus experience fewer subjective vitality and more significant psychological adjustment challenges than those who are non-lonely. Consistent with this study's 


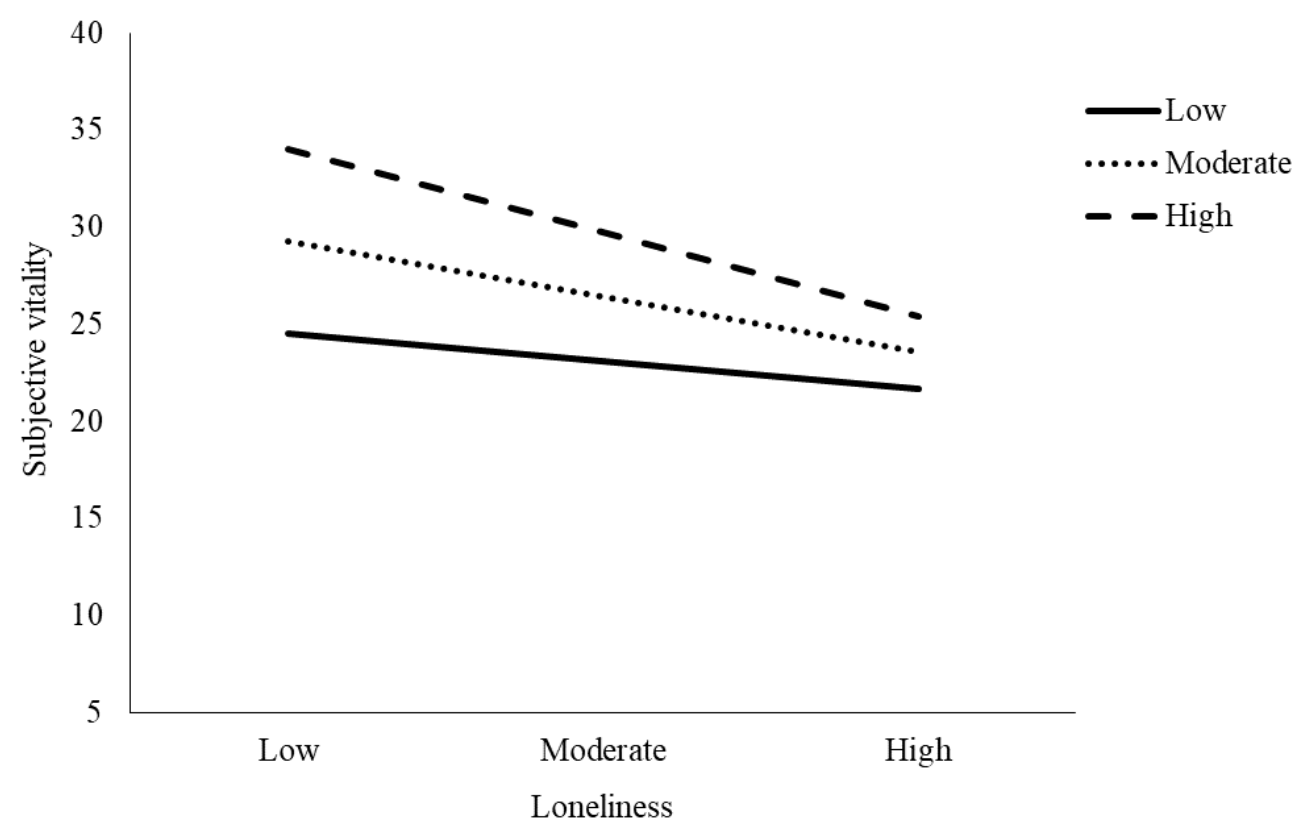

Figure 2. Moderating effect of college belonging

results, past research revealed that loneliness had impairment impacts on psychological well-being and adjustment. Feelings of loneliness were, for instance, associated with depressive symptoms (Kim et al., 2017; Moeller \& Seehuus, 2019; Richardson et al., 2017), aggressive behaviors (Yavuzer et al., 2019), and addictive behaviors (Habibi et al., 2018; Skues et al., 2016) in college students. Satici (2020) examined the mediating role of loneliness in the association between stress and subjective vitality and found the negative predictive effect of loneliness on Turkish college students' subjective vitality. People with positive social relationships with others also reported greater subjective vitality (Akin et al., 2016), and vitality serves as a mitigating mechanism in the association between social relationships and well-being in college students (Akın \& Akın, 2015).

Further, we found that subjective vitality mitigated the negative effect of loneliness on psychological adjustment. Higher subjective vitality was associated with fewer psychological adjustment challenges, and loneliness predicted psychological adjustment through college students' subjective vitality. Subjective vitality is a dynamic construct reflecting individual's subjective experience of being aliveness and physical and mental energy (Ryan \& Deci, 2008; Ryan \& Frederick, 1997). People with high subjective vitality are more active and productive, which supports better coping with challenges, enhances psychological well-being, and reduces psychological adjustment difficulties (Kawabata et al., 2017; Ryan \& Deci, 2008; Uğur et al.,
2019). Theoretically, subjective vitality is based on a psychological energy that is an essential resource for performing activities and facilitating better psychological well-being (Deci \& Ryan, 2000; Ryan \& Deci, 2008). People with high subjective vitality are more likely to regulate their purposive behaviors and actions, which, in turn, enhance their psychological adjustment and well-being (Arslan et al., 2020). Similar to the findings of this study, previous research indicated that subjective vitality was associated with psychological adjustment challenges, including addictive behaviors (Niemiec et al., 2010), psychological distress (Rouse et al., 2015), and school burnout (Saricam, 2015). Some research also focused on the mitigating role of subjective vitality on college students' outcomes in the context of adversities (Arslan et al., 2020). For example, Internet addiction was a significant predictor of subjective happiness through subjective vitality (Akin, 2012). Subjective vitality was also positively correlated with physical function and health-related quality of life and was negatively associated with depression, anxiety, and fatigue (Rouse et al., 2015). Hence, these results support that subjective vitality is an important mechanism that may help explain the association between loneliness and college students' psychological adjustment.

Lastly, findings from the current study revealed that college belongingness moderated the mediating role of subjective vitality in the association of feelings of loneliness with psychological adjustment challenges and served as a buffer against loneliness's impacts on 
subjective vitality. These findings support the notion that college belongingness may serve as a resilience factor in promoting psychological adjustment for young adults with negative life experiences, such as loneliness. A sense of belongingness is a primary human motivator, crucial for forming and maintaining positive social relationships (Baumeister \& Leary, 1995). College belongingness is a student's subjective experiences of being accepted, supported, and included by others in the university setting's social environment. Hence, college belongingness is essential for better psychological adjustment and well-being of young people, and people with a high sense of belonging reported fewer psychological adjustment challenges, such as depression, anxiety (Arslan et al., 2020; Arslan \& Tanhan, 2019; Davis et al., 2019; Tanhan, 2020) and behavioral problems, such as suicidal behaviors, conduct problems (Arslan, 2019; Arslan \& Tanhan, 2019; Olcoń et al., 2017; Rostosky et al., 2003; Tanhan, 2020). Alkan (2016), for example, found that college belongingness had significant correlations with loneliness, intention to drop out, and satisfaction with the university. College students with a high sense of belonging also exhibited more adaptive help-seeking strategies (Won et al., 2019) and fewer psychological difficulties (Pittman \& Richmond, 2007; Thompson et al., 2019).

Consistent with the present results, research further demonstrates that belongingness is an essential protective factor for psychological well-being and adjustment in the context of adversities (Backhaus et al., 2019; Civitci, 2015; Eisenberg et al., 2007; Nuttman-Shwartz, 2019; Zhang et al., 2020). For example, school belongingness was found as a protective factor in the relationship between loneliness and depressive symptoms (Baskin et al., 2010) and moderated the negative impacts of adverse experiences on psychological adjustment (Sargent et al., 2002; Torgerson et al., 2018; Zhang et al., 2020). In Tanhan's (2020) study, the college students also reported home "confinement and feeling stuck in their cities" (19\%) and "living in tower blocks" $(10 \%)$ that caused them to be and feel isolated from other people as some of the most important barriers during the COVID-19 pandemic. In contrast, some participants (9\%) reported "living in house with gardens" and "doing favors for other people" ( $9 \%$ ) that allowed them to socialize with others within a safe space as some of the most important facilitators during the pandemic. The evidence suggests that college belongingness is a power resource for fostering college students' psychological health and well-being has a buffering effect on the negative association of loneliness with psychological adjustment challenges.

\section{Limitations}

Results from this study are interpreted in light of some methodological limitations. The present study used a cross-sectional design that cannot ascertain a causal link between the study variables. A longitudinal design is warranted to provide additional insight into the association between the study variables. Secondly, selfreport instruments were used to collect the data, which is considered another limitation of the current study. Further research could be conducted to investigate of the relationship between the variables using multiple techniques (e.g., qualitative and quantitative). Further, this study only included young adults from a state university in a Turkish, urban area. Additionally, most participants were female, which may be considered a limitation for this study. Given this limitation, future research could be performed to examine the associations found in the current study with diverse and large samples, such as adolescents, and older adults.

\section{Implications for Future Research and Practice}

Findings from the study provide important implications for research and practice. The study's results show that subjective vitality mitigates the negative effect of loneliness on college students' psychological adjustment. Subjective vitality represents the energy, willingness, and aliveness of college students. Mental health providers could use subjective vitality as a coping strategy for improving the psychological wellbeing of young adults in university settings. They could focus on positive experiences that can enhance subjective vitality in young adults who exhibit more robust psychological adjustment challenges.

Further, the study results indicate that college belongingness has a buffering effect against the negative impacts of loneliness and moderated the mediating role of subjective vitality in the association between loneliness and psychological adjustment challenges in college students. These results suggest a need to develop more comprehensive intervention strategies for improving psychological health and wellbeing. Given the protective effect of college belongingness, the sense of belonging can be identified as an essential aspect of implementing positive psychology-based prevention and intervention services. Specifically, college belongingness could reduce the 
impacts of adverse experiences on the psychological health and well-being of young adults. Therefore, college belongingness could be integrated with positive psychology-based strategies to improve psychological flourishing in the face of negative experiences.

In conclusion, the present study results indicate that subjective vitality and college belongingness are important mechanisms that may help explain the association between loneliness and psychological wellbeing in college students during coronavirus pandemic. Therefore, strategies that promote young adults' level of belonging and subjective vitality could be increased to improve their psychological adjustment and wellbeing. At this point, counselors or other professions could design and develop preventions and interventions aimed at increasing subjective vitality and college belongingness, which fosters psychological well-being at university settings during this public health crisis.

\section{Compliance with Ethical Standards}

\section{Ethical Standards}

All study procedures involving human participants followed institutional and/or national research committee ethical standards and the 1964 Helsinki declaration and its later amendments or comparable ethical standards.

\section{Declaration of Conflicting Interests}

The authors declared no potential conflicts of interest with respect to the research, authorship, and/or publication of this article.

\section{Funding}

The author(s) received no financial support for the research, authorship, and/or publication of this article.

\section{ORCID}

Gökmen Arslan (iD https://orcid.org/0000-0001-94271554

Received: September 9, 2020

Accepted: October 13, 2020

Published Online: October 14, 2020

\section{References}

Akin, A. (2012). The relationships between internet Akin, A. (2012). The relationships between Internet addiction, subjective vitality, and subjective happiness. Cyberpsychology, Behavior, and Social Networking, 8(10), 404-410. https://doi.org/ 10.1089/cyber. 2011.0609

Akın, A., \& Akın, U. (2015). Friendship quality and subjective happiness: The mediator role of subjective vitality. Ëgitim ve Bilim, 40(177), 233242. https://doi.org/10.15390/EB.2015.3786

Akin, Ü., Akin, A., \& Uğur, E. (2016). Mediating role of mindfulness on the associations of friendship quality and subjective vitality. Psychological Reports 119(2), 516-526. https://doi.org/10.1177/ 0033294116661273

Alkan, N. (2016). Psychological sense of university membership: An adaptation study of the PSSM Scale for Turkish university students. The Journal of Psychology, 150(4), 431-449. https://doi.org/ 10.1080/00223980.2015.1087373

Allen, K.-A., Vella-Brodrick, D., \& Waters, L. (2016). Fostering school belonging in secondary schools using a socio-ecological framework. The Educational and Developmental Psychologist, 33(1), 97-121. https://doi.org/10.1017/edp.2016.5 Arslan, G. (2019). School belonging in adolescents: Exploring the associations with school achievement and internalising and externalising problems. Educational and Child Psychology, $36(4), 22-33$.

Arslan, G. (2020). School belongingness, well-being, and mental health among adolescents: Exploring the role of loneliness. Australian Journal of Psychology. https://doi.org/10.1111/ajpy.12274

Arslan, G., \& Duru, E. (2017). Initial development and validation of the School Belongingness Scale. Child Indicators Research, 10(4), 1043-1058. https://doi.org/10.1007/s12187-016-9414-y

Arslan, G., \& Tanhan, A. (2019). Ergenlerde okul aidiyeti, okul işlevleri ve psikolojik uyum arasındaki ilişkinin incelenmesi. Yaşadıkça Eğitim, 33(2), 318-332. https://doi.org/10.33 308/26674874.2019332127

Arslan, G., Yıldırım, M., \& Aytaç, M. (2020). Subjective vitality and loneliness explain how coronavirus anxiety increases rumination among college students. Death Studies. https://doi.org/10.1080/07481187.2020.1824204

Arslan, G., Allen, K.-A., \& Ryan, T. (2020). Exploring the impacts of school belonging on youth wellbeing and mental health among Turkish adolescents. Child Indicators Research. https://doi.org/10.1007/s12187-020-09721-z

Arslan, G., Yıldırım, M., Tanhan, A., Buluş, M., \& Allen, K. A. (2020). Coronavirus stress, optimismpessimism, psychological inflexibility, and psychological health: Psychometric properties of the Coronavirus Stress Measure. International Journal of Mental Health and Addiction. 
https://doi.org/10.1007/s11469-020-00337-6

Backhaus, I., Lipson, S. K., Fisher, L. B., Kawachi, I., \& Pedrelli, P. (2019). Sexual assault, sense of belonging, depression and suicidality among LGBQ and heterosexual college students. Journal of American College Health. https://doi.org/10.1080/07448481.2019.1679155

Baskin, T. W., Wampold, B. E., Quintana, S. M., \& Enright, R. D. (2010). Belongingness as a protective factor against loneliness and potential depression in a multicultural middle school. The Counseling Psychologist, 38(5), 626-651. https://doi.org/10.1v 177/0 011000009358459

Baumeister, R. F., \& Leary, M. R. (1995). The need to belong: Desire for interpersonal attachments as a fundamental human motivation. Psychological Bulletin, 117(3), 497-529. Doi?

Cacioppo, J. T., Hughes, M. E., Waite, L. J., Hawkley, L. C., \& Thisted, R. A. (2006). Loneliness as a specific risk factor for depressive symptoms: Cross-sectional and longitudinal analyses. Psychology and Aging, 21(1), 140-151. https://doi.org/10.1037/0882-7974.21.1.140

Çivitci, A. (2014). Positive affection and self-esteem in college students: The moderating role of college satisfaction and college belonging. Yuksekogretim Dergisi, $4(2)$,

102-109. https://doi.org/10.2399/yod.14.012

Civitci, A. (2015). Perceived stress and life satisfaction in college students: Belonging and extracurricular participation as moderators. Procedia-Social and Behavioral Sciences, 205, 271-281. https://doi.org/10.1016/j.sbspro.2015.0 9.077

Cruz, R. A., Peterson, A. P., Fagan, C., Black, W., \& Cooper, L. (2020). Evaluation of the Brief Adjustment Scale-6 (BASE-6): A measure of general psychological adjustment for measurement-based care. Psychological Services, 17(3), 332-342. https://doi.org/10.1037/ser0000 366

D’Agostino, R. B., Belanger, A., \& D’Agostino, R. B. (1990). A suggestion for using powerful and informative tests of normality. The American Statistician, 44(4), 316-321. https://doi.org/10.23 07/2684359

Davis, J. P., Merrin, G. J., Ingram, K. M., Espelage, D. L., Valido, A., \& El Sheikh, A. J. (2019). Examining pathways between bully victimization, depression, \& school belonging among early adolescents. Journal of Child and Family Studies,
28(9), 2365-2378. https://doi.org/10.1007/s 1082 6-019- 01340-9

Deci, E. L., \& Ryan, R. M. (2000). The "what" and "why" of goal pursuits: Human needs and the selfdetermination of behavior. Psychological Inquiry, 11(4), 227-268. https://doi.org/10.1207/S1532 7965PLI1104_01

Doğan, T., Çötok, N. A., \& Tekin, E. G. (2011). Reliability and validity of the Turkish Version of the UCLA Loneliness Scale (ULS-8) among university students. Procedia - Social and Behavioral Sciences, 15, 2058-2062. https://doi.org/10.1016/j.sbspro.2011.04.053

Doman, L. C. H., \& Le Roux, A. (2012). The relationship between loneliness and psychological well-being among third-year students: A crosscultural investigation. International Journal of Culture and Mental Health, 5(3), 153-168. https://doi.org/1 0.1080/17542863.2011.579389

Eisenberg, M. E., Ackard, D. M., \& Resnick, M. D. (2007). Protective factors and suicide risk in adolescents with a history of sexual abuse. The Journal of Pediatrics, 151(5), 482-487. https://doi.org/10.1016/j .jpeds.2007.04.033

Field, A. (2009). Discovering statistics using SPSS. Sage.

Goodenow, C. (1993). The psychological sense of school membership among adolescents: Scale development and educational correlates. Psychology in the Schools, 30(1), 79-90. doi:

Goodenow, C., \& Grady, K. E. (1993). The relationship of school belonging and friends' values to academic motivation among urban adolescent students. The Journal of Experimental Education, 62(1), 60-71. https://doi.org/10.10 80/00220973.1993.9943831

Habibi, M., Hosseini, F., Darharaj, M., Moghadamzadeh, A., Radfar, F., \& Ghaffari, Y. (2018). Attachment style, perceived loneliness, and psychological well-being in smoking and nonsmoking university students. Journal of Psychology: Interdisciplinary and Applied, 152(4), 226-236. https://doi.org/10.1080/00223 980.2 018.1446894

Hayes, A. F. (2018). Introduction to mediation, moderation, and conditional process analysis: A regression-based approach. Guilford.

Hooper, D., Coughlan, J., \& Mullen, M. R. (2008). Structural equation modelling: Guidelines for determining model fit. Electronic Journal of 
Business Research Methods, 6(1), 53-60.

Houghton, S., Hattie, J., Carroll, A., Wood, L., \& Baffour, B. (2016). It hurts to be lonely! Loneliness and positive mental wellbeing in Australian rural and urban adolescents. Journal of Psychologists and Counsellors in Schools, 26(1), 52-67. https://doi.org/10.1017/jgc.2016.1

Hu, L., \& Bentler, P. M. (1999). Cutoff criteria for fit indexes in covariance structure analysis: Conventional criteria versus new alternatives. Structural Equation Modeling: A Multidisciplinary Journal, $\quad 6(1), \quad 1-55$. https://doi.org/10.1080/10705519909540118

Jackson, C. E., \& DiPlacido, J. (2020). Vitality as a mediator between diet quality and subjective wellbeing among college students. Journal of Happiness Studies. https://doi.org/10.1007/s1090 2-019-00150-6

Kawabata, M., Yamazaki, F., Guo, D. W., \& Chatzisarantis, N. L. D. (2017). Advancement of the Subjective Vitality Scale: Examination of alternative measurement models for Japanese and Singaporeans, 27(12), 1793-1800. Scandinavian Journal of Medicine and Science in Sports. https://doi.org/10.1 111/sms.12760

Kim, E. Y., Cho, I., \& Kim, E. J. (2017). Structural equation model of smartphone addiction based on adult attachment theory: Mediating effects of loneliness and depression. Asian Nursing Research, 11(2), 92-97. https://doi.org/10.1016/j. anr.2017.05.0 02

Luchetti, M., Lee, J. H., Aschwanden, D., Sesker, A., Strickhouser, J. E., Terracciano, A., \& Sutin, A. R. (2020). The trajectory of loneliness in response to COVID-19. American Psychologist, 75(7), 897908. http://dx.doi.org/10.1037/amp0000690

Malone, G. P., Pillow, D. R., \& Osman, A. (2012). The general belongingness scale (GBS): Assessing achieved belongingness. Personality and Individual Differences, 52(3), 311-316. https://doi.org/10.1016/j.paid.2011.10.027

Mellor, D., Stokes, M., Firth, L., Hayashi, Y., \& Cummins, R. (2008). Need for belonging, relationship satisfaction, loneliness, and life satisfaction. Personality and Individual Differences, 45(3), 213-218. doi:

Moeller, R. W., \& Seehuus, M. (2019). Loneliness as a mediator for college students' social skills and experiences of depression and anxiety. Journal of Adolescence, 73, 1-13. https://doi.org/10.1 016/j.adolescence.2019.03.006

Mounts, N. S. (2004). Contributions of parenting and campus climate to freshmen adjustment in a multiethnic sample. Journal of Adolescent Research, 19(4), 468-491. https://doi.org/10.11 77/0743558403258862

Niemiec, C. P., Ryan, R. M., Patrick, H., Deci, E. L., \& Williams, G. C. (2010). The energization of healthbehavior change: Examining the associations among autonomous self-regulation, subjective vitality, depressive symptoms, and tobacco abstinence. Journal of Positive Psychology, 5(2), 122-138. https://doi.org/10.10 80/1743976090 3569162

Nuttman-Shwartz, O. (2019). The moderating role of resilience resources and sense of belonging to the school among children and adolescents in continuous traumatic stress situations. Journal of Early Adolescence, 39(9), 1261-1285. https:// doi.org/10.1177/0272431618812719

Olcoń, K., Kim, Y., \& Gulbas, L. E. (2017). Sense of belonging and youth suicidal behaviors: What do communities and schools have to do with it? Social Work in Public Health, 32(7), 432-442. https://doi.org/10.1080/19371918.2017.1344602

Özdemir, U., \& Tuncay, T. (2008). Correlates of loneliness among university students. Child and Adolescent Psychiatry and Mental Health, 2(1), 29. https://doi.org/10.1186/1753-2000-2-29

Peltzer, K., \& Pengpid, S. (2017). Loneliness: Its correlates and associations with health risk behaviours among university students in 25 countries. Journal of Psychology in Africa, 27(3), 247-255. https://doi.org/10.1080/14330237.201 7.1321851

Pittman, L. D., \& Richmond, A. (2007). Academic and psychological functioning in late adolescence: The importance of school belonging. The Journal of Experimental Education, 75(4), 270-290. https://doi.org/10.3200/JEXE.75.4.270-292

Preacher, K. J., \& Hayes, A. F. (2008). Asymptotic and resampling strategies for assessing and comparing indirect effects in multiple mediator models. Behavior Research Methods, 40(3), 879-891. https://doi.org/10.3758/BRM.40.3.879

Preacher, K. J., Rucker, D. D., \& Hayes, A. F. (2007). Addressing moderated mediation hypotheses: Theory, methods, and prescriptions. Multivariate Behavioral Research, 42(1), 185-227. https://doi.org/10.1080/002 73170701341316

Richardson, T., Elliott, P., \& Roberts, R. (2017). Relationship between loneliness and mental health in students. Journal of Public Mental Health, 16(2), 48-54. https://doi.org/10.1108/ JPMH-03- 


\section{6-0013}

Rostosky, S. S., Owens, G. P., Zimmerman, R. S., \& Riggle, E. D. B. (2003). Associations among sexual attraction status, school belonging, and alcohol and marijuana use in rural high school students. Journal of Adolescence, 26(6), 741-751. https://doi.org/10.1016/j.adolescence.2003.09.002

Rouse, P. C., Veldhuijzen Van Zanten, J. J. J. C. S., Ntoumanis, N., Metsios, G. S., Yu, C., Kitas, G. D., \& Duda, J. L. (2015). Measuring the positive psychological well-being of people with rheumatoid arthritis: a cross-sectional validation of the Subjective Vitality Scale. Arthritis Research \& Therapy, $\quad 17(1), \quad 312 . \quad$ https://doi.org/10.1 186/s13075-015-0827-7

Russell, D., Cutrona, C. E., Rose, J., \& Yurko, K. (1984). Social and emotional loneliness: An examination of Weiss's typology of loneliness. Journal of Personality and Social Psychology, 46(6), 1313-1321. doi

Russell, D., Peplau, L. A., \& Cutrona, C. E. (1980). The revised UCLA Loneliness Scale: Concurrent and discriminant validity evidence. Journal of Personality and Social Psychology, 39(3), 472480. https://doi.org/10.1037/0022-3514.39.3.472

Ryan, R. M., \& Deci, E. L. (2008). From ego depletion to vitality: Theory and findings concerning the facilitation of energy available to the self. Social and Personality Psychology Compass, 2 (2008): 702-717https://doi.org/10.1111/j.1751004.2008. 00098.x

Ryan, R. M., \& Frederick, C. (1997). On energy, personality, and health: Subjective vitality as a dynamic reflection of well-being. Journal of Personality, 65(3), 529-565. https://doi.org/ 10.1111/j.1467-6494.1997.tb00326.x

Salama-Younes, M. (2011). Positive mental health, subjective vitality and satisfaction with life for French physical education students. World Journal of Sport Sciences, 4(2), 90-97.

Salama-Younes, M., \& Hashim, M. (2018). Passion, vitality and life satisfaction for physically active old adults. Journal of Positive Psychology, 13(3), 309-319 https://doi.org/10.1080/17439760.2017 .1291848

Sargent, J., Williams, R. A., Hagerty, B., Lynch-Sauer, J., \& Hoyle, K. (2002). Sense of belonging as a buffer against depressive symptoms. Journal of the American Psychiatric Nurses Association, 8 (4), 120-129. https://doi.org/10.1067/mpn.2002.1
27290

Saricam, H. (2015). Mediating role of self-efficacy on the relationship between subjective vitality and school burnout in Turkish adolescents. Educational Research Association: The International Journal of Educational Researchers, 6(1), 1-12.

Satici, S. A. (2019). Facebook addiction and subjective well-being: A study of the mediating role of shyness and loneliness. International Journal of Mental Health and Addiction, 17(1), 41-55. https://doi.org/10.1 007/s11469-017-9862-8

Satici, S. A. (2020). Hope and loneliness mediate the association between stress and subjective vitality. Journal of College Student Development. https://doi.org/10.1353/csd.2020.0019

Shochet, I. M., Smith, C. L., Furlong, M. J., \& Homel, R. (2011). A prospective study investigating the impact of school belonging factors on negative affect in adolescents. Journal of Clinical Child \& Adolescent Psychology, 40(4), 586-595. https://doi.org/10.1080/15374416.2011.581616

Skues, J., Williams, B., Oldmeadow, J., \& Wise, L. (2016). The effects of boredom, loneliness, and distress tolerance on problem internet use among university students. International Journal of Mental Health and Addiction, 14(2), 167-180. https://doi.org/10.1007/s11469-015-9568-8

Stevens, J. P. (2009). Applied multivariate statistics for the social sciences. Routledge.

Tanhan, A. (2018). Beginning counsellors' supervision in counseling and challenges and supports they experience: Based on developmental models. Adiyaman Üniversitesi Eğitim Bilimleri Dergisi, $8(1)$, 49-71. https://doi.org/10.17984/adyuebd.336222

Tanhan, A. (2019). Acceptance and commitment therapy with ecological systems theory: Addressing Muslim mental health issues and wellbeing. Journal of Positive Psychology and Wellbeing, 3(2), 197-219. https://doi.org/10.47 602/jpsp.v3i2.172

Tanhan, A. (2020). COVID-19 sürecinde online seslifoto (OSF) yöntemiyle biyopsikososyal manevi ve ekonomik meseleleri ve genel iyi oluş düzeyini ele almak: OSF'nin Türkçeye uyarlanmas1. [Utilizing online photovoice (OPV) methodology to address biopsychosocial spiritual economic issues and wellbeing during COVID-19: Adapting OPV to Turkish.] Turkish Studies, 15(4), 
1029-1086.

7/TurkishStudies.44451

Tay, L., \& Jebb, A. (2017). Scale development. In S. Rogelberg (Ed.), The SAGE encyclopedia of industrial and organizational psychology. Sage.

Thompson, K., Wood, D., \& Davis MacNevin, P. (2019). Sex differences in the impact of secondhand harm from alcohol on student mental health and university sense of belonging. Addictive Behaviors, 89, 57-64. https://doi.org/ 10.1016/j.a ddbeh.2018.09.012

Torgerson, C. N., Love, H. A., \& Vennum, A. (2018). The buffering effect of belonging on the negative association of childhood trauma with adult mental health and risky alcohol use. Journal of Substance Abuse Treatment, 88, 44-50. https://doi.org /10.1016/j.jsat.2018.02.005

Uğur, E., Kaya, Ç., \& Özçelik, B. (2019). Subjective vitality mediates the relationship between respect toward partner and subjective happiness on teachers. Universal Journal of Educational Research, 7(1), 126-132. https://doi.org/10.13 189/ujer.2019.070117

Uysal, R., Saricam, H., \& Akin, A. (2014). Öznel Zindelik Ölçeği Türkçe formunun psikometrik özellikleri. Muğla Sıtkı Koçman Üniversitesi Sosyal Bilimler Enstitüsü Dergisi, 33, 136-146.

Uysal, Recep, Satici, S. A., \& Akin, A. (2013). Mediating effect of facebook $\AA$ addiction on the relationship between subjective vitality and subjective happiness. Psychological Reports, 113(3), 948-953. https://doi.org/10.2466/02.09.18 .PR0.113x32z3

Weiss, R. S. (1973). Loneliness: The experience of emotional and social isolation. MIT Press.

Won, S., Hensley, L. C., \& Wolters, C. A. (2019). Brief research report: Sense of belonging and academic help-seeking as self-regulated learning. The Journal of Experimental Education https://doi.org/10.1080/00220973.2019.1703095

World Health Organization. (2020). WHO coronavirus disease (COVID-19) dashboard. https://covid19. who.int/

Worthington, R. L., \& Whittaker, T. A. (2006). Scale development research. The Counseling Psychologist, 34(6), 806-838. https://doi.org/10.1 $177 / 0011000006288127$

Yavuzer, Y., Albayrak, G., \& Kilıçarslan, S. (2019). Relationships amongst aggression, self-theory, loneliness, and depression in emerging adults. Psychological Reports, 122(4), 1235-1258. https://doi.org/10.1177/0033294118784866
Yildirım, M., \& Solmaz, F. (2020a). COVID-19 burnout, COVID-19 stress and resilience: Initial psychometric properties of COVID-19 Burnout Scale. Death Studies. https://doi.org/10.1080/07 481187.2020 .1818885

Y1ldırım, M. \& Solmaz, F. (2020b). Testing a Turkish adaption of the Brief Psychological Adjustment Scale and assessing the relation to mental health. Psikoloji Çalışmalarl, 40(2), 1-23.

Yildirim, M., \& Arslan, G. (2020). Exploring the associations between resilience, dispositional hope, subjective well-being, and psychological health among adults during early stage of COVID19. PsyArXiv, 1-27. https://doi.org/ 10.31234/osf.io/vpu5q

Yıldırım, M., \& Güler, A. (2020a). Positivity mechanism explains how COVID-19 perceived risk increases death distress and reduces happiness. Personality and Individual Differences, 110347. https://doi.org/10.1016/j. paid.2020.110347

Y1ldırım, M., \& Güler, A. (2020b). COVID-19 severity, self-efficacy, knowledge, preventive behaviors, and mental health in Turkey. Death Studies. https://doi.org/10.1080/07481187.2020. 1793434

Yildirim, M., Ozaslan, A., \& Arslan, G. (2020). Perceived risk and mental health problems among healthcare professionals during COVID-19 pandemic: Exploring the mediating effects of resilience and coronavirus fear. PsyArXiv, 1-25. https://doi.org/10.31234/osf.io/ 84xju

Zhang, H., Liu, M., \& Long, H. (2020). Child maltreatment and suicide ideation in rural China: the roles of self-compassion and school belonging. Child and Adolescent Social Work Journal. https://doi.org/10.1007/s10560-020-00679-z 